\title{
ADVANTAGES OF CONTINUOUS HYPERPOLARIZED ARREST WITH PINACIDIL OVER ST. THOMAS' HOSPITAL SOLUTION DURING PROLONGED ISCHEMIA
}

Mark Jayawant, MD

Edward R. Stephenson, Jr., MD

Ralph J. Damiano, Jr., MD
Objective: The potassium channel opener, pinacidil, has been shown to be an effective cardioplegic agent over short periods of ischemia. However, clinical settings typically involve longer ischemic periods. This study tested the hypothesis that myocardial protection with a potassium channel opener is feasible during prolonged periods of arrest and is comparable with the traditional St. Thomas' Hospital solution. Methods: With a blood-perfused, isolated rabbit heart model, hearts underwent 1 hour of global normothermic ischemia followed by $\mathbf{3 0}$ minutes of reperfusion. During ischemia, three different cardioplegic solutions were administered either intermittently by infusion every 20 minutes or as continuous low-flow cardioplegia $(150 \mathrm{ml}$ total volume in all groups): (1) Krebs-Henseleit solution alone (control), (2) Krebs-Henseleit solution + pinacidil (50 $\mu \mathrm{mol} / \mathrm{L}$ ), or (3) St. Thomas' Hospital solution. Initial potassium channel opener infusions contained 5 $\mathrm{mmol} / \mathrm{L}$ procaine. Postreperfusion systolic function (percent of developed pressure) was measured. Compliance changes were integrated from the end-diastolic pressure/volume relationships. Results: For intermittent cardioplegia, only St. Thomas' Hospital solution improved function (62.5\% $4.0 \%)$ versus control $(43.6 \% \pm 3.3 \%, p<0.001)$. However, with continuous cardioplegia, only pinacidil $(75.6 \% \pm 4.8 \%)$ exceeded control $(62.7 \% \pm$ $2.2 \%, p<0.001$ ) and was significantly better than St. Thomas' Hospital solution. Compared with the intermittent control group, all other groups showed significant preservation of preischemic diastolic properties. Conclusions: Myocardial protection during a longer, more clinically relevant ischemic period is feasible with a potassium channel opener only when it is given continuously. Continuous low-flow pinacidil cardioplegia was superior to St. Thomas' Hospital solution given either as an intermittent or continuous infusion. (J Thorac Cardiovasc Surg 1998;116:131-8)
Dota otassium cardioplegia has been the foundation of myocardial protection for the last quarter of a century. Conventional hyperkalemic solutions depolarize the cell membrane to induce rapid electromechanical arrest, thereby markedly reducing cellular energy expenditure during the ischemic period.

From the Department of Surgery, Division of Cardiothoracic Surgery, The Milton S. Hershey Medical Center, Pennsylvania State University, Hershey, Pa.

Received for publication Feb. 24, 1997; revisions requested May 12, 1997; revisions received July 17, 1997; accepted for publication Feb. 24, 1998.

Address for reprints: Ralph J. Damiano, Jr., MD, Chief, Division of Cardiothoracic Surgery, The Milton S. Hershey Medical Center, Penn State Geisinger Health System, P.O. Box 850, Hershey, PA 17033.

Copyright (C) 1998 by Mosby, Inc.

$0022-5223 / 98 \$ 5.00+0 \quad \mathbf{1 2 / 1 / 8 9 8 0 2}$
However, despite acceptable results, depolarizing solutions possess fundamental shortcomings. Sodium influx during arrest activates sodium-calcium exchangers, which, along with calcium leak from the sarcoplasmic reticulum, contribute to intracellular calcium overload. ${ }^{1,2}$ The altered cellular environment provokes compensatory metabolic processes, notably activation of sodium and calcium ion pumps, which expend energy reserves in the ischemic cell. ${ }^{2,3}$ These ionic and metabolic disturbances have been implicated as etiologic factors in many pathologic processes including activation of catabolic enzyme systems, abnormal regulation of intracellular second messengers, myocardial stunning, calcium-activated arrhythmogenic currents, and myocardial edema. ${ }^{4-7}$ It is our hypothesis that the ideal cardioplegic solution should produce readily reversible, rapid electromechanical arrest while arresting the myo- 


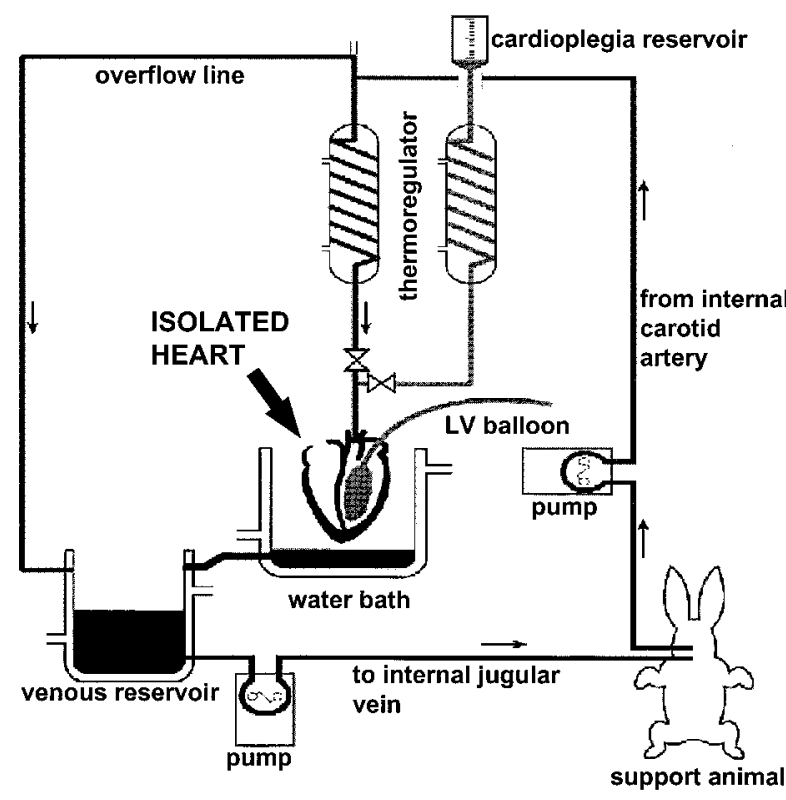

Fig. 1. Schematic diagram of the parabiotic isolated heart apparatus. $L V$, Left ventricular.

cyte near its natural, resting membrane potential. At these "hyperpolarized" potentials, transmembrane ion gradients are balanced and metabolic demand is minimal. Also, an ideal agent should take advantage of the myocyte's intrinsic cardioprotective response to ischemia.

In 1983, cardiac cells were discovered to contain a unique class of metabolically linked potassium channels that possess intrinsic cardioprotective properties. ${ }^{8}$ These adenosine triphosphate (ATP)-sensitive potassium channels were shown to open during cellular ischemia. The potassium efflux caused action potential shortening, decreased calcium influx, and subsequent contractile failure, which constituted an intrinsic energy-sparing mechanism during ischemia. $^{9}$

ATP-sensitive potassium channels are activated by a diverse group of pharmacologic agents collectively called potassium channel openers (PCOs). Previous work in our laboratory has shown PCOs to be effective cardioplegic agents that adequately protect the myocardium during global ischemia. ${ }^{10-13}$ However, these studies involved only short periods of surgical ischemia. Clinical settings typically involve longer ischemic periods. The present study tested the hypothesis that myocardial protection with a PCO is feasible during prolonged periods of arrest and is comparable to the traditional hyperkalemia St. Thomas' Hospital cardioplegic solution.

\section{Methods}

Adult New Zealand White rabbits of either sex, weighing 2.8 to $3.1 \mathrm{~kg}$, were used in this study. All animals received humane care in American Association for the Accreditation of Laboratory Animal Care-approved, United States Department of Agriculture-registered (No. 23-R-02) facilities in compliance with the "Principles of Laboratory Animal Care" formulated by the National Society for Medical Research and the "Guide for the Care and Use of Laboratory Animals" prepared by the Institute of Laboratory Animal Resources and published by the National Institutes of Health (NIH Publication No. 86-23, revised 1985.)

\section{Experimental preparation}

Preparation of the support animal. The support animal was anesthetized, attached to a ventilator, and given heparin as previously described. ${ }^{13}$

The right femoral artery was cannulated; the cannula was connected to a pressure transducer (model P231D; Gould Inc., Cleveland, Ohio), and continuous invasive monitoring (Sirecust 404-1A; Siemens Medical Systems, Inc., Danvers, Mass.) of blood pressure was begun. A systolic blood pressure above $80 \mathrm{~mm} \mathrm{Hg}$ was maintained by transfusion of either blood collected from the donor animal or Plasma-Lyte electrolyte solution (Baxter Healthcare Corp., Deerfield, Ill.).

The left internal jugular vein and the left carotid artery were cannulated. Cannulas were attached to silicone rubber tubing (internal diameter $=0.125$ inch; Baxter Scientific Products, McGaw Park, Ill.) and positioned in roller pumps. Arterial blood was pumped (Masterflex model 7013; Cole Parmer Inst. Co., Chicago, Ill.) to perfuse a modified Langendorff apparatus described previously (Fig. 1). ${ }^{12}$ Column height was $80 \mathrm{~cm}$. Effluent from the column was returned to the internal jugular vein of the support animal. Indomethacin $(1 \mathrm{mg} / \mathrm{gm})$ (INN: indometacin) was administered to the support animal to augment blood pressure stability. ${ }^{14}$

Preparation of the donor animal and isolated heart. The donor animal was anesthetized, intubated, attached to a ventilator, and given heparin. ${ }^{13} \mathrm{~A}$ rapid cardiectomy was accomplished through a median sternotomy. The aorta was cannulated with the heart suspended from a modified Langendorff apparatus, and blood perfusion was begun. A fluid-filled latex balloon was placed into the left ventricle and secured with a purse-string suture in the mitral valve anulus. The balloon was connected via polyethylene tubing to a pressure transducer (model P231D; Gould Inc.) and amplifier (model 13-4615-50; Gould Inc.). The zeropressure reference was set at the level of the aortic valve. Two needle electrodes were secured in the right atrial appendage and connected to a pacemaker (model 5320; Medtronic, Inc., Minneapolis, Minn.); the heart rate was maintained at a constant rate of 180 to 240 beats/minute. Two additional electrodes were placed on the left ventricular epicardium to monitor the bipolar ventricular electrogram. The electrodes were connected to an isolated preamplifier (model 11-G5407-58; Gould Inc.) and a universal amplifier (model 13-4615-58; Gould Inc.) and filtered between 0.05 and $1000 \mathrm{~Hz}$. The pressure and electrogram waveforms were displayed continuously and 
Table I. Times to mechanical and electrical arrest

\begin{tabular}{|c|c|c|c|c|c|c|c|}
\hline & \multicolumn{4}{|c|}{ Intermittent cardioplegia } & \multicolumn{3}{|c|}{ Continuous cardioplegia } \\
\hline & $\begin{array}{l}\text { Control } \\
(n=6)\end{array}$ & $\begin{array}{c}\text { Pin } \\
(n=8)\end{array}$ & $\begin{array}{l}\text { Pin/pro } \\
(n=4)\end{array}$ & $\begin{array}{c}\text { St. T } \\
(n=6)\end{array}$ & $\begin{array}{l}\text { Control } \\
(n=6)\end{array}$ & $\begin{array}{c}\text { Pin } \\
(n=6)\end{array}$ & $\begin{array}{c}\text { St. T } \\
(n=6)\end{array}$ \\
\hline $\mathrm{EA}(\mathrm{sec})$ & $1788 \pm 435$ & $30 \pm 2^{*}$ & $31 \pm 1^{*}$ & $48 \pm 8^{*}$ & $3101 \pm 388$ & $50 \pm 9^{*}$ & $47 \pm 7^{*}$ \\
\hline $\mathrm{MA}(\mathrm{sec})$ & $587 \pm 108$ & $31 \pm 6^{*}$ & $34 \pm 4^{*}$ & $42 \pm 7^{*}$ & $2928 \pm 382$ & $45 \pm 8^{*}$ & $55 \pm 11^{*}$ \\
\hline
\end{tabular}

Results are expressed as mean \pm SEM. Control, K-H solution only; pin, pinacidil cardioplegia; pin/pro, procaine added to all doses of pinacidil; St. T, St. Thomas' Hospital cardioplegia; $E A$, electrical arrest; $M A$, mechanical arrest.

*Statistically different from both controls (analysis of variance, $p<0.001$ ).

digitized in real time with a WINDAQ/200 system (DATAQ Instruments, Akron, Ohio) at a sampling rate of $1000 \mathrm{~Hz}$. Coronary flow was measured with an in-line flow probe and continuously monitored with a flowmeter (model T206; Transonic Systems, Inc., Ithaca, N.Y.).

The heart was enclosed in a water-jacketed beaker, and myocardial temperature was measured with a probe placed in the right ventricle (model BAT 8; Bailey Instruments, Saddle Brook, N.J.). Myocardial temperature was maintained at $37^{\circ} \mathrm{C}$ by adjusting the temperature of the water bath (model D1; Haake Co., Berlin, Germany).

Experimental protocol. Hearts that did not generate a systolic pressure exceeding $80 \mathrm{~mm} \mathrm{Hg}$ at an end-diastolic pressure (EDP) of $10 \mathrm{~mm} \mathrm{Hg}$ were excluded from the study. After instrumentation, hearts were given $30 \mathrm{~min}-$ utes to equilibrate. Baseline data were acquired. Intracavitary left ventricular pressure waveforms and left ventricular bipolar electrograms were recorded over seven balloon volumes, each corresponding to a fixed intracavitary $\operatorname{EDP}(0,2.5,5,10,15,20$, and $25 \mathrm{~mm} \mathrm{Hg})$. Hearts were randomized to undergo cardioplegic infusion by one of seven modes before the onset of 60 minutes of global ischemia $\left(32^{\circ}\right.$ to $\left.34^{\circ} \mathrm{C}\right)$. The groups were divided into those receiving intermittent cardioplegia and those receiving continuous cardioplegia. In the intermittent group, 50 $\mathrm{ml}$ of cardioplegic solution was given every 20 minutes. In the hearts receiving continuous cardioplegia, a $50 \mathrm{ml}$ bolus of cardioplegic solution was followed by a continuous infusion of $1.67 \mathrm{ml} / \mathrm{min}$ (infusion pump model Minipulse 2; Gilson, Middleton, Wis.) for a total of $100 \mathrm{ml}$ delivered continuously over the ischemic period. The total amount of cardioplegic solution delivered was identical in the intermittent and continuous groups. For each infusion group, hearts received one of three different cardioplegic regimens: (1) control solution consisting of Krebs-Henseleit solution alone $(n=6) ;(2)$ hyperkalemic cardioplegia with St. Thomas' Hospital solution $(n=6)$; or (3) hyperpolarizing cardioplegia with $50 \mu \mathrm{mol} / \mathrm{L}$ of pinacidil (continuous, $n=6$; intermittent, $n=8$ ). The delivery medium for pinacidil cardioplegic solutions was KrebsHenseleit solution $\left(\mathrm{NaCl} 118.5 \mathrm{mmol} / \mathrm{L}, \mathrm{NaHCO}_{3} 25\right.$ $\mathrm{mmol} / \mathrm{L}, \mathrm{KCl} 3.2 \mathrm{mmol} / \mathrm{L}, \mathrm{MgSO}_{4}, 1.2 \mathrm{mmol} / \mathrm{L}, \mathrm{KH}_{2} \mathrm{PO}_{4}$ $1.2 \mathrm{mmol} / \mathrm{L}, \mathrm{CaCl}_{2} 2.5 \mathrm{mmol} / \mathrm{L}$, and glucose $5.5 \mathrm{mmol} / \mathrm{L}$ ).

Prolonged electromechanical activity with pinacidil cardioplegia has been documented in our laboratory. ${ }^{13}$ Previous studies from our laboratory have shown that this persistent electromechanical activity can be reversibly eliminated with sodium channel blockade using $5 \mathrm{mmol} / \mathrm{L}$ procaine. ${ }^{15}$ Therefore, the initial pinacidil infusion contained $5 \mathrm{mmol} / \mathrm{L}$ procaine. A separate group was treated with intermittent boluses of $50 \mu \mathrm{mol} / \mathrm{L}$ pinacidil and was administered procaine in all doses $(5 \mathrm{mmol} / \mathrm{L}$ at $0 \mathrm{~min}$ utes, $2 \mathrm{mmol} / \mathrm{L}$ at 20 minutes and 40 minutes; $n=4)$ to eliminate transient electromechanical activity during reinfusion and to determine whether procaine augmented PCO cardioprotection during prolonged ischemia. Pinacidil was provided by Leo Pharmaceuticals, Billup, Denmark. St. Thomas' Hospital solution (Plegisol; Na 110 $\mathrm{mEq} / \mathrm{L}, \mathrm{Cl} 160 \mathrm{mEq} / \mathrm{L}, \mathrm{K} 16 \mathrm{mEq} / \mathrm{L}, \mathrm{Ca} 2.4 \mathrm{mEq} / \mathrm{L}, \mathrm{Mg} 32$ $\mathrm{mEq} / \mathrm{L}$ ) was provided by Abbott Laboratories, Chicago, Illinois.

After 1 hour of global ischemia, hearts were reperfused for 30 minutes. The heart was defibrillated, if necessary. Intracavitary left ventricular pressure waveforms and electrograms were recorded over the identical range of balloon volumes recorded during baseline data acquisition. At the conclusion of the study, a sample of the left ventricle was excised, blotted, weighed, and dried until a constant dry weight was reached. Myocardial edema was expressed as the percent tissue water in the following equation:

$\% \mathrm{H}_{2} \mathrm{O}=($ Wet weight - Dry weight $) /$ Wet weight

\section{Data analysis}

End-systolic pressure. The end-systolic pressure (ESP) of a beat was defined and averaged as previously described. ${ }^{10-13}$ Mean ESP was calculated for each of the seven baseline and seven postreperfusion balloon volumes. ESP versus volume data were fitted to a linear ESP-volume relationship (ESPVR) with a least-squares linear regression:

$$
\mathrm{ESP}=\mathrm{E}_{\max } \times \mathrm{V}+\mathrm{k}
$$

where $\mathrm{E}_{\max }$ is the slope of the ESPVR, $\mathrm{V}$ is the volume, and $\mathrm{k}$ is the $\mathrm{y}$-axis intercept of the ESPVR.

End-diastolic pressure. The EDP of a beat was determined and averaged for 10 consecutive beats to calculate the mean EDP. ${ }^{13}$ The EDP versus volume data were fitted to a linear EDP-volume relationship with a least-squares linear regression:

$$
\mathrm{EDP}=\mathrm{m}\left(\mathrm{V}-\mathrm{V}_{0}\right)
$$

where $\mathrm{m}$ is the slope of the EDP-volume relationship, $\mathrm{V}$ is the volume, and $\mathrm{V}_{0}$ is the balloon volume at which EDP is zero, or the $\mathrm{x}$-axis intercept. ${ }^{16,17}$

Developed pressure. Developed pressure in the left ventricle (DP) was defined as the difference between ESP and EDP for a given beat. The DP of 10 beats was averaged 


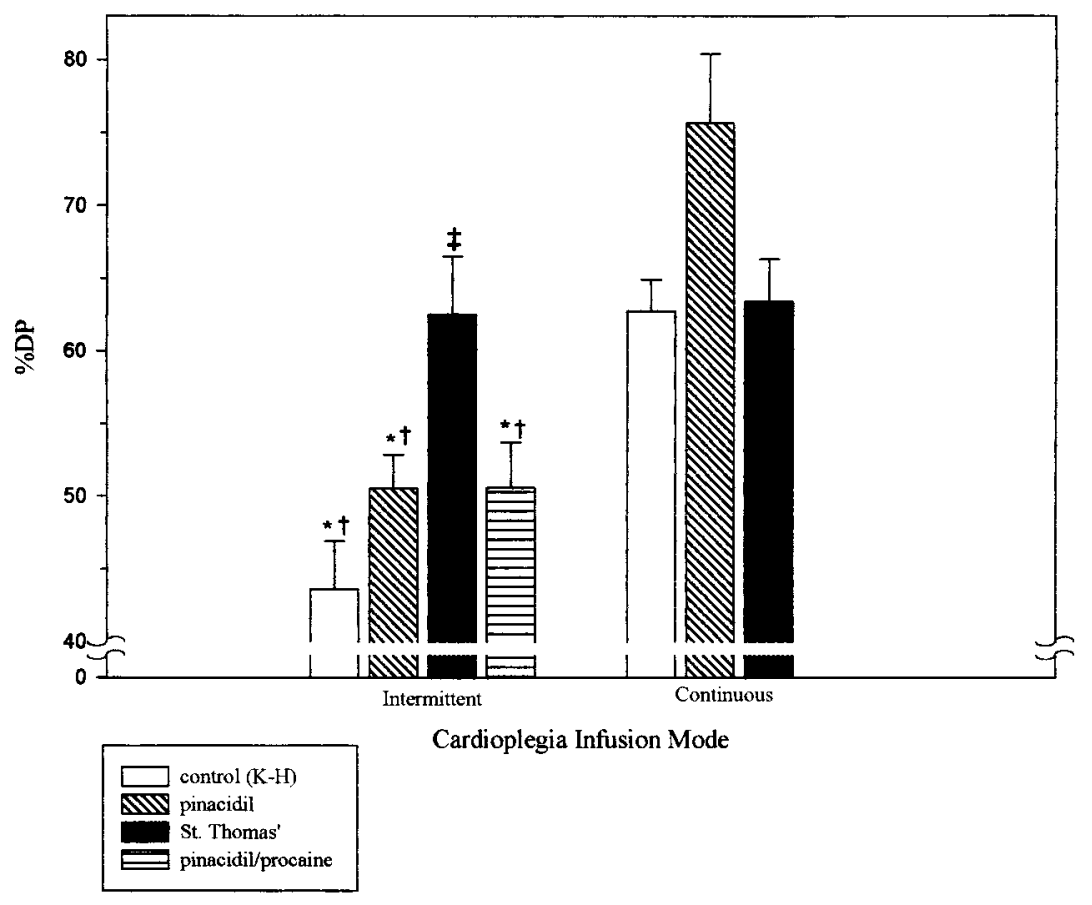

Fig. 2. Postischemic systolic function expressed as the percent recovery of left ventricular developed pressure $(\% D P)$, grouped by method of cardioplegic infusion. All results are expressed as mean \pm SEM. Pinacidil/procaine means that procaine was added to all infusions. Statistically significant difference by one-way analysis of variance $(p<0.001)$ versus intermittent St. Thomas' Hospital solution $(*)$, continuous St. Thomas’ Hospital solution $(\dagger)$, respective control $(\ddagger)$, or all other groups $(\S) . K-H$, Krebs Henseleit.

for each balloon volume. The DP versus volume data were fitted to a linear pressure-volume relationship with the following regression:

$\mathrm{DP}=\mathrm{ESP}-\mathrm{EDP}=\left(\mathrm{E}_{\max } \times \mathrm{V}+\mathrm{k}\right)-\mathrm{m}\left(\mathrm{V}-\mathrm{V}_{0}\right)$

Recovery of DP. The recovery of DP, expressed as a percentage, was calculated as the ratio of the postreperfusion developed pressure to the mean baseline developed pressure at the same balloon volume. The average percent recovery of developed pressure (\%DP) was determined using the trapezoidal rule as described previously. ${ }^{18}$

Diastolic compliance. Because this model incorporates a wide range of volumes to establish functional parameters over an entire pressure-volume relationship, changes in compliance at a single, fixed volume were validated by analyzing an integrated spectrum of diastolic changes. Integrated areas of the left ventricular end-diastolic pressure (LVEDP)-volume relationships were calculated and expressed as a ratio of baseline to after reperfusion. The mean LVEDP ratio was determined with the following definite integral:

$$
\text { Mean LVEDP ratio }=\int_{\mathrm{V}_{\mathrm{a}}}^{\mathrm{V}_{\mathrm{b}}} P_{r} P_{b} \mathrm{dV} /\left(\mathrm{V}_{\mathrm{b}}-\mathrm{V}_{\mathrm{a}}\right)
$$

where $V_{b}$ is the largest matching postreperfusion balloon volume, $\mathrm{V}_{\mathrm{a}}$ is the smallest matching postreperfusion bal- loon volume, $\mathrm{P}_{\mathrm{b}}$ is LVEDP at baseline, and $\mathrm{P}_{\mathrm{r}}$ is the LVEDP after reperfusion. A ratio of 1 therefore reflects no change in diastolic compliance.

Statistical analysis. Results are expressed as the mean \pm standard error of the mean. Analysis of variance was used for multiple comparisons. When appropriate, the Kruskal-Wallis analysis of variance on ranks was used as a nonparametric alternative. Pairwise comparisons between groups were made with a Student-NewmanKeuls post test. Comparisons to a single control value were made with a Dunnett's post-test. A $t$ test was used for comparisons between two sets, with a Mann-Whitney rank sum test as a nonparametric alternative. A $\chi^{2}$ analysis of contingency tables was used to compare mutually exclusive, categoric data where appropriate.

\section{Results}

There were no significant differences in $\mathrm{pH}$, oxygen tension, carbon dioxide tension, serum sodium, potassium, calcium, or hematocrit in the support animal between baseline data acquisition and after 30 minutes of reperfusion. Furthermore, there were no significant differences in postischemic systolic function, diastolic compliance, onset of electromechanical arrest, or tissue water content between the 
Table II. Postischemic LVEDP measured by the fixed volume comparison and validated by integration of LVEDP versus volume relationships before and after ischemia

\begin{tabular}{|c|c|c|c|c|c|c|c|}
\hline & \multicolumn{4}{|c|}{ Intermittent cardioplegia } & \multicolumn{3}{|c|}{ Continuous cardioplegia } \\
\hline & $\begin{array}{l}\text { Control } \\
(n=6)\end{array}$ & $\begin{array}{c}\text { Pin } \\
(n=8)\end{array}$ & $\begin{array}{l}\text { Pin/pro } \\
(n=4)\end{array}$ & $\begin{array}{c}\text { St. } T \\
(n=6)\end{array}$ & $\begin{array}{l}\text { Control } \\
(n=6)\end{array}$ & $\begin{array}{c}\text { Pin } \\
(n=6)\end{array}$ & $\begin{array}{c}\text { St. } T \\
(n=6)\end{array}$ \\
\hline $\begin{array}{l}\mathrm{LVEDP}_{5}(\mathrm{~mm} \mathrm{Hg}) \\
\mathrm{d}\left(\mathrm{P}_{\mathrm{b}} / \mathrm{P}_{\mathrm{r}}\right) \mathrm{dV}\end{array}$ & $\begin{array}{l}31.2 \pm 12.1 \\
0.42 \pm 0.17\end{array}$ & $\begin{array}{c}4.8 \pm 0.9^{*} \\
1.00 \pm 0.08^{*}\end{array}$ & $\begin{array}{c}4.8 \pm 1.7^{*} \\
1.09 \pm 0.23^{*}\end{array}$ & $\begin{aligned} 4.3 & \pm 0.4^{*} \\
1.04 & \pm 0.07^{*}\end{aligned}$ & $\begin{array}{c}6.0 \pm 1.4^{*} \\
0.82 \pm 0.10^{*}\end{array}$ & $\begin{array}{c}7.2 \pm 3.1^{*} \\
0.86 \pm 0.23^{*}\end{array}$ & $\begin{aligned} 5.3 & \pm 0.5^{*} \\
0.98 & \pm 0.06^{*}\end{aligned}$ \\
\hline
\end{tabular}

Results are expressed as mean \pm SEM. Control, K-H solution; pin, pinacidil; pin/pro, pinacidil, intermittent infusion/procaine in all three doses; St T, St. Thomas' solution; $L V E D P_{5}$, postreperfusion LVEDP at identical volume corresponding to baseline $\mathrm{LVEDP}$ of $5 \mathrm{~mm} \mathrm{Hg} ; d\left(P_{b} / P_{r}\right) d V$, definite integral of the baseline to postreperfusion LVEDP versus volume relationships; $P_{b}$, LVEDP at baseline; $P_{r}$, LVEDP after reperfusion, respectively. A ratio of 1 reflects no diastolic change.

*Statistically different from intermittent control (analysis of variance, $p=0.003$ for LVEDP $; p=0.006$ for $d\left[\mathrm{P}_{\mathrm{b}} / \mathrm{P}_{\mathrm{r}}\right] \mathrm{dV}$ ).

intermittent pinacidil groups with and without the additional procaine doses.

Temporal aspects of the development of electromechanical arrest. All pinacidil and St. Thomas' Hospital groups demonstrated significantly shorter times to electrical arrest over controls (Table I). There were no significant differences in times to electromechanical arrest between PCO and St. Thomas' Hospital solutions. Of the hearts treated with continuous, slow infusion of Krebs-Henseleit solution only, mechanical and electrical activity persisted throughout the entire ischemic period for $50 \%$ and $67 \%$ of the hearts, respectively. Transient return of low-amplitude electrical activity was usually observed after pinacidil infusion at 20 and 40 minutes of ischemia. This effect was not observed when $2 \mathrm{mmol} / \mathrm{L}$ procaine was added to the infusate.

Reperfusion arrhythmias. Only two of 42 hearts comprising this study exhibited ventricular fibrillation on reperfusion (pinacidil, one continuous and one intermittent). These were electrically converted to sinus rhythm. There were no statistically significant differences between groups in the incidence of reperfusion ventricular fibrillation.

Postischemic systolic function. Cardioplegia with continuous low-dose pinacidil resulted in improved recovery compared with control and St. Thomas' Hospital cardioplegia, regardless of the method of infusion (Fig. 2). However, intermittent pinacidil cardioplegia was ineffective, showing no improvement over the control group. Unlike pinacidil, the protective effects of St. Thomas' Hospital solution were not altered by the method of infusion.

Postischemic diastolic compliance. Changes in diastolic compliance were measured with a fixedvolume comparison (Table II). LVEDP was compared at an identical, fixed balloon volume at base- line and after reperfusion. The fixed volume corresponded to a baseline LVEDP of $5 \mathrm{~mm} \mathrm{Hg}$. No statistical differences in baseline values were shown between groups. However, after reperfusion, the intermittent control group showed a significantly higher mean LVEDP than all other groups. There were no differences in compliances between any of the cardioplegia groups.

The fixed-volume comparison was validated by an alternative analysis that compared the entire range of matched volumes. Integrated areas of the diastolic pressure-volume relationships, expressed as a ratio of baseline to postreperfusion, were calculated. A baseline-to-postreperfusion mean LVEDP ratio of 1 reflected no change in diastolic compliance (Table II). Compared with the intermittent-infusion control group, all other groups demonstrated significant preservation of baseline diastolic compliance, in agreement with the single fixed-volume analysis.

Coronary flow. All groups exhibited a significant increase in coronary flow immediately on reperfusion. Unlike St. Thomas' Hospital cardioplegia, pinacidil produced a prolonged hyperemic state on reperfusion (Fig. 3). These patterns were not significantly affected by the method of infusion.

Myocardial tissue water. The mean percent tissue water for the seven groups was as follows: intermittent Krebs-Henseleit solution (control), $80.4 \% \pm 0.4 \%$; continuous slow Krebs-Henseleit solution (continuous control), 79.6\% $\pm 1.0 \%$; pinacidil, $78.9 \% \pm 0.4 \%$; pinacidil/procaine (all doses), $79.3 \% \pm 0.4 \%$; pinacidil, continuous lowdose infusion, $78.5 \% \pm 0.4 \%$; St. Thomas' Hospital solution, $79.7 \% \pm 0.2 \%$; and St. Thomas' Hospital solution continuous infusion, $78.4 \% \pm 0.5 \%$. No significant differences in tissue water content were detected among the groups. 

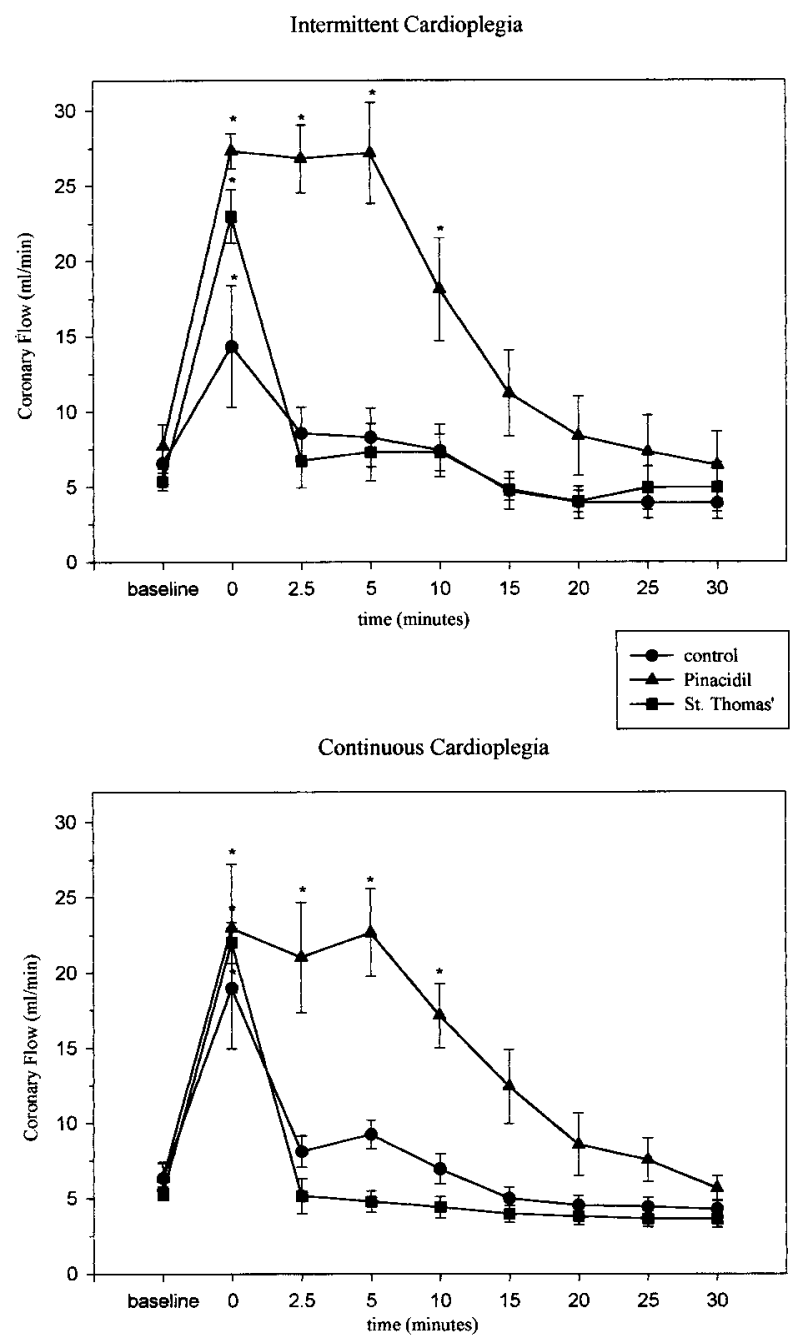

Fig. 3. Reperfusion coronary flow. All results are expressed as mean \pm SEM. Baseline is before ischemia is begun. *Significantly increased flow compared with baseline $(p<0.001$, one-way repeated measures analysis of variance).

\section{Discussion}

Principles of hyperpolarized arrest. The cardiac cell is hyperpolarized at rest. PCOs, which hyperpolarize the membrane, theoretically minimize ongoing metabolic activity that can lead to ischemic injury by approximating the resting state of the myocyte. Under these circumstances, transmembrane ionic gradients are balanced, ion channel flux minimal, and ATP-driven pumps largely inactive. ${ }^{19}$ Our laboratory has shown that PCO cardioplegia was either better than or as protective as the traditional St. Thomas' Hospital cardioplegia over short ischemic periods. ${ }^{10,12,13}$ However, the clinically rel- evant question of whether hyperpolarized arrest is cardioprotective during prolonged periods of ischemia had not been investigated before this study.

Recent efforts to optimize myocardial protection during cardioplegic arrest have focused on normothermic continuous or near-continuous infusion of standard depolarizing solutions. This avoids the theoretically detrimental aspects of hypothermia $^{20-24}$ and provides a continuous supply of substrate and oxygen during electromechanical arrest, potentially abolishing ischemia and minimizing reperfusion injury. ${ }^{21,22}$ However, current techniques of continuous normothermic cardioplegia have several shortcomings, including the need for large volumes, high potassium loads, and difficulty visualizing the operative field. ${ }^{24}$ It is our hypothesis that hyperpolarizing cardioplegic solutions may solve some of these problems because of their superior cardioprotection, allowing for lower volumes and asanguineous delivery. This study was designed to examine both intermittent and continuous hyperpolarized and depolarized cardioplegia over prolonged periods of ischemia.

Recovery of systolic function with intermittentinfusion pinacidil. With intermittent infusion, pinacidil cardioplegia showed a trend toward improved functional recovery, but this was not statistically different from control. This is in direct contrast to our previous results that looked at shorter intervals of ischemia in which PCO cardioplegia always resulted in improved postischemic recovery. ${ }^{10-13}$ There are several possible explanations for pinacidil's failure to provide adequate myocardial protection.

The loss of pinacidil's cardioprotective effects with prolonged ischemia may be related to the prolonged and recurrent electrical activity typical of PCO cardioplegia. However, this hypothesis was refuted by the fact that the addition of procaine to all pinacidil infusions eliminated all electrical activity but did not improve functional recovery. This is consistent with our previous observations ${ }^{15}$ and can be explained by the fact that the oxygen requirements needed to maintain electrical activity comprise less than $1 \%$ of the total basal oxygen consumption of the heart. ${ }^{25}$

Another possibility is that pinacidil does not result in hyperpolarized arrest in this model. However, a previous study ${ }^{26}$ that examined changes in membrane potential in isolated myocyte preparations exposed to PCOs clearly demonstrated that hyperpolarization occurs. However, it is possible 
that pinacidil's membrane hyperpolarization is not maintained over longer ischemic periods. Further investigation is necessary to clarify this issue.

Finally, it is possible that PCO membrane hyperpolarization does not produce an energy-sparing state as originally postulated. A recent study in our laboratory supports this hypothesis. Reperfusion myocardial oxygen consumption in hearts arrested with pinacidil cardioplegia was found to be higher than those arrested with potassium cardioplegia. ${ }^{27}$ Thus PCOs may convey their benefit via ionic (i.e., prevention of calcium overload) rather than metabolic mechanisms. ${ }^{27}$ Over short periods, this ionic benefit may be sufficient to provide improved systolic recovery despite ongoing metabolic demand.

Recovery of systolic function with continuousinfusion pinacidil. When the same agents were given as continuous cardioplegia, the results were strikingly different. The enhanced functional recovery in the control group over its intermittent equivalent was expected because there was a continuous, albeit slow, delivery of substrate (Fig. 2). However, the delivery of St. Thomas' Hospital solution as continuous cardioplegia provided negligible myocardial protection and was no better than the continuous control infusion of Krebs-Henseleit solution alone. In contrast, pinacidil demonstrated a significant improvement in its cardioprotective capacity when applied as continuous cardioplegia. Although the same molar amount of cardioplegic solution was delivered to the myocardium regardless of the infusion method, the slower continuous infusion may have provided a steadier supply of substrate than higher-flow intermittent infusions. Additionally, continuous slow infusion may avoid myocardial toxicity by providing a continuous "washout" of toxic metabolites that is not as efficient with periodic bolus infusions. Moreover, during intermittent infusion, there may have been a less effective delivery of cardioplegic solution to the myocardium because of the shunting of solution away from the capillary network as a result of the higher flow rates. Finally, continuous infusion may have produced a more constant state of hyperpolarization that would prevent calcium overload and other ionic abnormalities associated with depolarized potentials.

Postischemic recovery of diastolic properties. Because this model incorporates a wide range of volumes to establish systolic and diastolic pressurevolume regressions, changes in compliance were examined by comparing changes in the integrated diastolic pressure-volume curves (Table II). Pinacidil, in all doses, demonstrated protective effects on diastolic properties, which were similar to the St. Thomas' Hospital solution groups. This is in agreement with our previous work. ${ }^{10-13}$

Postreperfusion arrhythmias. PCOs have been shown to be proarrhythmic. ${ }^{12,27}$ By decreasing action potential duration and therefore refractory period, these agents are thought to provoke reentrant ventricular arrhythmias, which represents a potential drawback of this class of drugs. In this study, however, pinacidil did not significantly increase the incidence of ventricular fibrillation. It is possible that the antiarrhythmic effect of procaine was responsible for the distinct lack of PCO-induced ventricular fibrillation. Although further studies are needed to confirm this hypothesis, sodium channel blockade may emerge as an essential additive to PCO cardioplegia.

Coronary flow. Pinacidil was associated with increased, prolonged reperfusion coronary blood flow when compared with St. Thomas' Hospital solution (Fig. 3), which reconfirms previous results from our laboratory. ${ }^{13}$ The increase in reperfusion coronary blood flow continued for the first 10 minutes of reperfusion before returning to baseline. The method of delivery did not alter this effect. The reasons for this hyperemic response may be due to several factors including the known vasodilatory effect of pinacidil on vascular smooth muscle, ${ }^{28}$ improved endothelial protection, ${ }^{29}$ or a greater oxygen debt during ischemia. ${ }^{27}$

Although the continuous and intermittent pinacidil groups demonstrate a similar reperfusion coronary blood flow profile, ventricular recovery of developed pressure was significantly enhanced only in the continuous group. In agreement with other studies, ${ }^{30,31}$ our study suggests the cardioprotective effect of pinacidil is not related to its vasodilatory effect.

Advantages and disadvantages of the blood-perfused isolated heart Langendorff model. The advantages and drawbacks concerning this model have been previously described. ${ }^{12,13}$ The more physiologic nature of this model is a distinct advantage over nonparabiotic and crystalloid-perfused models. However, care should be taken in extrapolating results from in vitro studies to the clinical setting. To determine the clinical feasiblility of pinacidil cardioplegia, in vivo studies are clearly needed. 


\section{Summary}

The method of delivery appeared to play a pivotal role in the ability of pinacidil to protect the heart during prolonged crossclamping. Pinacidil was ineffective as an intermittent-infusion cardioplegic agent. The role of pinacidil in future myocardial protection strategies will require further investigation into its dependency on continuous infusion and its ability to minimize myocardial metabolism during global ischemia.

\section{REFERENCES}

1. Drewnowska K, Clemo HF, Baumgarten CM. Prevention of myocardial intracellular edema induced by St. Thomas' Hospital cardioplegic solution. J Mol Cell Cardiol 1991;23:121521.

2. Damiano RJ. The electrophysiology of ischemia and cardioplegia: implications for myocardial protection. J Card Surg 1995;10(suppl):101-9.

3. Reimer KA, Jennings RB. Myocardial ischemia, hypoxia and infarction. In: Fozzard HA, Haber E, Jennings RB, Katz AM, Morgan HE, editors. The heart and cardiovascular system. New York: Raven; 1992. p. 1973-5.

4. Bolli R. Mechanism of myocardial stunning. Circulation 1990;82:723-8.

5. Marban E. Pathogenetic role for calcium in stunning? Cardiovasc Drugs Ther 1991;5:891-5.

6. Gettes LS, Cascio WE. Effect of acute ischemia on cardiac electrophysiology. In: Fozzard HA, Haber E, Jennings RB, Katz AM, Morgan HE, editors. The heart and cardiovascular system. New York: Raven; 1992. p.2021-54.

7. Foglia RP, Steed DL, Follette DM, Deland E, Buckberg GD. Iatrogenic myocardial edema with potassium cardioplegia. J Thorac Cardiovasc Surg 1979;78:217-22.

8. Noma A. ATP-regulated $\mathrm{K}^{+}$channels in cardiac muscle. Nature 1983;305:147-8.

9. Gross GJ, Auchampach JA. Role of ATP dependent potassium channels in myocardial ischaemia. Cardiovasc Res 1992;26:1011-6.

10. Jayawant AM, Lawton JS, Hsia P, Damiano RJ. Hyperpolarized cardioplegic arrest with nicorandil: advantages over other potassium channel openers. Circulation 1997; 96(Suppl):II240-5.

11. Cohen NM, Wise RM, Wechsler AS, Damiano RJ. Elective cardiac arrest with a hyperpolarizing adenosine triphosphatesensitive potassium channel opener. J Thorac Cardiovasc Surg 1993;106:317-28.

12. Maskal SL, Cohen NM, Hsia PW, Wechsler AW, Damiano RJ. Hyperpolarized cardiac arrest with a potassium-channel opener, aprikalim. J Thorac Cardiovasc Surg 1995;110:108395.

13. Lawton J, Sepic J, Allen C, Hsia P, Damiano R. Myocardial protection with potassium channel openers is as effective as St. Thomas' solution in the rabbit heart. Ann Thorac Surg 1996;62:31-9.

14. Goto Y, Slinker BK, LeWinter MM. Decreased contractile efficiency and increased nonmechanical energy cost in hyperthyroid rabbit heart. Circ Res 1990;66:999-1011.
15. Maskal SL, Fields CE, Cohen NM, Damiano RJ. Persistent electrical activity during hyperpolarized cardiac arrest does not affect post ischemic myocardial recovery. Surg Forum 1995;46:222-4.

16. Moon M, DeAnda A, Daughters G, Ingels N, Miller D. Experimental evaluation of different chordal preservation methods during mitral valve replacement. Ann Thorac Surg 1994;58:931-44.

17. Shintani H, Glatz S. Effect of disrupting the mitral apparatus on left ventricular function in dogs. Circulation 1993;87:200115.

18. Stark P. Numerical integration. In: Introduction to numerical methods. New York: Macmillian Publishing; 1970. p. 196-8.

19. Katz AM. The cardiac action potential. In: Physiology of the heart. 2nd ed. New York: Raven Press; 1992. p. 438-72.

20. Lichtenstein SV, Salerno TA, Slutsky AS. Pro: warm continuous cardioplegia is preferable to intermittent hypothermic cardioplegia for myocardial protection during cardiopulmonary bypass. J Cardiothorac Anesth 1990;4:279-81.

21. Ting W, Spotnitz AJ, Mackenzie JW, Chen WH, Conway RS. Protection of the acutely injured heart-deleterious effects of hypothermia. J Surg Res 1994;56:108-11

22. Liu X, Engelman RM, Rousou JA, Plack JE, Deaton DW, Das DK. Normothermic cardioplegia prevents intracellular calcium accumulation during cardioplegic arrest and reperfusion. Circulation 1994;90:316-20.

23. Tonz M, von Segesser LK, Mihaljevic T, Leskosek B, Turina M. Coronary artery resistance and oxygen uptake during reperfusion: Is there any difference between warm and cold cardioplegia? Thorac Cardiovasc Surg 1993;41:270-3.

24. Massie MT, Darrell JC, DiMarco RF, et al. Normothermic retrograde continuous cardioplegia for myocardial protection during cardiopulmonary bypass, a modified technique. Tex Heart Inst J 1993;20:89-93.

25. Klocke FJ, Braunwald E, Ross J. Oxygen cost of electrical activity of the heart. Circ Res 1966;18:357-65.

26. Jiang C, Mochizuki S, Poole-Wilson PA, Harding SE, MacLeod KT. Effect of lemakalim on action potentials, intracellular calcium, and contraction in guinea pig and human cardiac myocytes. Cardiovasc Res 1994;28:851-7.

27. Lawton JS, McClain LC, Maier GW, Hsia P, Damiano RJ. Postischemic myocardial oxygen consumption in hearts protected with hyperpolarizing cardioplegia. Circulation 1997; 96(Suppl):247-52.

28. Gollasch M, Rostislav B, Ried C, et al. Pinacidil relaxes porcine and human coronary arteries by activating ATPdependent potassium channels in smooth muscle cells. J Pharmacol Exp Ther 1995;275:681-92.

29. Ryman T, Petersson J, Andersson K, Brandt L, Hogestatt ED. Effects of pinacidil on cerebral and mesenteric arteries: influence of the endothelium. Naunyn Schmiedebergs Arch Pharmacol 1993;348:298-304.

30. Sargent CA, Sleph PG, Dzwonczyk S, Normandin D, Antonaccio MJ, Grover GJ. Cardioprotective effects of the cyanoguanidine potassium channel opener P-1075. J Cardiovasc Pharm 1993;22:564-70.

31. Saltman AE, Krukenkamp IB, Gaudette GR, Levitsky S. Phenylephrine reverses the vasodilatory effect of potassium channel openers yet preserves their preconditioning properties [abstract]. Circulation 1996;94(Suppl):I415. 